\title{
Aproximaciones a la relación exclusión social y desigualdad social en Tacna
}

\author{
Approaches to the relationship social exclusion and social \\ inequality in Tacna
}

\author{
Oscar Panty Neyra \\ ${ }^{2}$ Omar Nieto Cardenas \\ ${ }^{3}$ Nery Zapana Ancota \\ ${ }^{4}$ Carlos Rojas Hosttas
}

ORCID: 0000-0003-3850-897X

ORCID: 0000-0003-4436-145X

\section{RESUMEN}

Con el presente estudio se puso en relieve la relación entre la exclusión social y la desigualdad social en Tacna, ciudad fronteriza ubicada en el extremo sur peruano que colinda con el Estado de Chile. Se entiende por exclusión social a la situación de privación de acceso a los bienes y servicios, así como a la disminución o pérdida de los derechos esenciales que experimentan los individuos de un grupo respecto a otros grupos en mejor situación. La exclusión social implica la existencia de jerarquías sociales, lo que se traduce como desigualdad social. En Tacna, la desigualdad social es muy pronunciada. Los grupos que se encuentran en la base de la pirámide económica también se encuentran en la base de las pirámides política y cultural, evidenciando una situación de pobreza manifestada como carencia de elementos esenciales para la subsistencia y el desarrollo personal, además de la insuficiencia de instrumentos para superar tal situación diametralmente opuesta a la bonanza de la minoría ubicada en la cúspide de la pirámide en general.

Palabras claves: Desigualdad social, exclusión social, pobreza.

\section{ABSTRACT}

With the present study it puts of relief the relationship between the social exclusion and the social inequality in Tacna, a border city located in the extreme south of Peru that share a border with the State of Chile. Social exclusion is understood as the situation of privation of the access to goods and services, as well as the decrease or loss of the essential rights that individuals in one group experience with respect to another groups in a better situation. In Tacna, Social inequality is very pronounced. The groups that are at the base of the economic pyramid are also at the base of the political and cultural pyramids showing a situation of manifest poverty as a lack of essential elements for subsistence and the personal development, in addition to the lack of instruments to overcome such a situation diametrical opposed to the minority prosperity located at the top of the pyramid in general.

Keywords: Social inequality, social exclusion, poverty.

\footnotetext{
${ }^{1}$ Universidad Nacional Jorge Basadre Grohmann. Tacna-Perú. E-mail: opanty@hotmail.com

${ }^{2}$ Universidad Nacional Jorge Basadre Grohmann. Tacna-Perú. E-mail: omarnieto_aqp@ @hotmail.com

${ }^{3}$ Universidad Nacional Jorge Basadre Grohmann. Tacna-Perú. E-mail: neryzapana65gmail.com

${ }^{4}$ Universidad Nacional Jorge Basadre Grohmann. Tacna-Perú.
}

Presentado: 14/10/19, Aprobado: 27/11/19 


\section{INTRODUCCIÓN}

Para determinar la relación exclusión social desigualdad social en Tacna, se procedió, en primer lugar, a la delimitación del área de investigación en la ciudad-capital, comprendiendo los sectores urbanos del distrito del cercado y los distritos Ciudad Nueva, Alto de la Alianza y Gregorio Albarracín Lanchipa, con una población ascendente a 270500 personas en el año 2016. Durante el trabajo de campo se aplicó una encuesta a 400 personas, de 18 a 70 años en la modalidad de muestreo al azar.

Este trabajo, que se desarrolla con el método de análisis coyuntural estructural, cobra importancia dada la agudización del drama humano en Tacna por la persistencia de los fenómenos de exclusión y desigualdad social. Un conocimiento más profundo de la naturaleza de estos fenómenos nos puede llevar a la formulación de sus alternativas de solución. Y, consecuentemente, a elevar el interés y el compromiso individual y colectivo para allanar el camino hacia el horizonte de las reivindicaciones del pueblo de Tacna.

\section{OBJETIVOS}

El objetivo general fue:

- Determinar la exclusión social y sus efectos en la desigualdad social de la ciudad de Tacna.

Los objetivos específicos fueron los siguientes:

- Identificar los tipos y niveles de exclusión social en la sociedad de la ciudad de Tacna.

- Analizar las manifestaciones de la desigualdad social en la ciudad de Tacna.

- Precisar la incidencia que tiene el modelo de modernización liberal, tanto en la concentración como en la distribución de los activos económicos, políticos y culturales relativos a los componentes de la sociedad de Tacna.

- Establecer la relación entre exclusión y desigualdad social en la ciudad de Tacna.

\section{ANTECEDENTES}

Fue en Europa, ya iniciada la segunda mitad de siglo XX, que se empezó a utilizar el término exclusión social en referencia a una imagen dual de la sociedad, en donde frente a un sector que está integrado con el goce de derechos y libertades se encuentra otro, privado, postergado o marginado de tales condiciones. Se le atribuye a Rene Lenoir (1974) el mérito de haber contribuido a la generalización del concepto exclusión social con su obra Les exclus:Un Frangaise sur dix.

En Latinoamérica de los años 90, aparece Danae de los Ríos con el ensayo Exclusión social y políticas sociales: una mirada analítica, el mismo que fue presentado en el Taller de Exclusión Social que la Organización Internacional del Trabajo (OIT) organizó en Santiago de Chile en diciembre de 1995. Para entonces, se afirmaba que la exclusión social comprende tanto "la denegación de los derechos sociales como las privaciones materiales. Consiguientemente, abarca no solo la falta de acceso de bienes y servicios, vinculada con la pobreza y la insatisfacción de las necesidades básicas, sino también con la exclusión de la seguridad, la justicia, la representación y la ciudadanía" (OIT, 1995).

Por otra parte, se sostuvo que la exclusión corresponde a "un proceso que surge a partir de un debilitamiento progresivo o un quiebre definitivo o duradero de los lazos que unen a los sujetos a la sociedad a la que pertenecen, de modo tal que se establece una división entre los que están dentro y quienes están fuera de ella" (De los Ríos, 1995). Asimismo, "la exclusión dice relación con la forma de integración que construye cada sociedad, da cuenta de la sociedad y de cómo se realiza la relación entre las personas y la sociedad" (De los Ríos, 1995). En el Perú de 1995, Denis Sulmont también se incorpora al estudio de la exclusión social con el trabajo Exclusión social y empleo: notas para un debate, trabajo que al año siguiente fue incluido en el estudio La exclusión social y desigualdad en el Perú, elaborado por encargo de la OIT. Sulmont sostiene: "El concepto de exclusión social se refiere a la acción y al efecto de impedir la participación de ciertas categorías de personas en aspectos considerados como valiosos de la vida colectiva. Indica una negación o ruptura de lazos de reciprocidad entre determinados individuos y una colectividad. Expresa un proceso de extrañamiento que da lugar a la conformación de grupos sociales segmentados." 
Sulmont (1995) diferencia los tres tipos de exclusión que han concitado la atención de los científico - sociales en la época del capitalismo tardío de las sociedades industrializadas, como en las periféricas y emergentes:

Exclusión económica, "una modalidad dominante de organización económica en la medida que los sujetos no tienen acceso a los medios que les permiten participar activamente en los sistemas productivos (unidades empresariales y de trabajo) y en los mercados básicos que corresponden a esta organización dominante. Tales medios comprenden diferentes activos: tierra, capital físico, crédito y capacidades humanas". Exclusión ciudadana, "cuando los sujetos sociales carecen de los derechos formales y reales, garantizados por una autoridad legítima, que les permite ejercer su libertad, participar en las decisiones y desenvolverse en la vida social". Comprende los derechos: civiles, políticos, sociales y económicos. Exclusión cultural, "cuando algunas personas son percibidas por otras como inferiores $\mathrm{y}$, de acuerdo a esta percepción, reciben un trato diferenciado y humillante en sus relaciones sociales. Un sector social discrimina a otro para defender una situación de superioridad, justificando esta en base a criterios biológicos, morales y/o culturales, tales como: la edad, el género, la raza, el origen social o la religión."

$\mathrm{Y}$, en cuanto a la desigualdad social, Sulmont indica que se debe al acceso diferenciado a los activos económicos, políticos y culturales. "Los procesos de exclusión social son claves para entender la génesis de las desigualdades. Pero a su vez, la desigualdad social tiende a provocar reacciones de defensa de los grupos privilegiados y de resistencia de los desfavorecidos, lo cual contribuye a rigidizar la estructura social y reproducir las desigualdades. En este caso, desigualdad y exclusión se retro-alimentan. Pero puede ocurrir también que las diferencias sociales sean parcialmente compensadas y reducidas, como consecuencia de la acción social y política".

Otro trabajo de importancia es Pobreza y exclusión social: una aproximación al caso peruano. Artículo de Iris Roca Rey y Belissa
Rojas (2002). El artículo se inicia con las siguientes interrogantes: “¿Quiénes podrían estar sufriendo de la exclusión social en el Perú? ¿De qué están excluidos? ¿Todos los pobres están excluidos? ¿La exclusión social los afecta a todos por igual? ¿Cuál es la diferencia entre un pobre excluido y uno que no lo está? ¿Por qué es relevante diferenciarlos? ¿Qué implica la exclusión social? ¿Afecta esta exclusión a la autoconfianza y capacidad de superar los problemas asociados con la pobreza?"

Respecto al concepto exclusión social, las autoras sostienen que designa a ciertos grupos "cuya calidad de vida y oportunidades de participar en la sociedad han sido disminuidas o bloqueadas. No tienen acceso a los beneficios de las instituciones y servicios sociales". La exclusión social presenta tres dimensiones: a) Relatividad: grupos excluidos de algo en relación a otros que no lo están, b) Agencia: grupos que se autoexcluyen o los excluyen otros, c) Dinámica: grupos con pocas posibilidades para el futuro, situación que, de relacionarse con la pobreza, se puede transmitir a otras generaciones.

Finalmente, las autoras arriban a las siguientes conclusiones:

"Existe una estrecha relación entre pobreza y exclusión social, aunque las dimensiones de la exclusión pueden variar significativamente al interior de los diversos grupos que componen la sociedad, incluyendo a los grupos de pobreza extrema. En este sentido, la importancia de determinar quiénes se han visto excluidos y de qué manera han sido y están siendo afectados, debe ser reconocida y calculada. De igual modo, se plantea la necesidad de saber de qué están siendo excluidos y cuáles son las medidas y programas que puedan contribuir a disminuir los niveles de exclusión social."

"Los pobres y además excluidos, son extremadamente vulnerables en la medida que pueden estar entrampados en la pobreza y transmitirla a futuras generaciones."

"Estos grupos vulnerables deben recibir especial atención en pos de superar su estado mediante programas integrales de inclusión. Por ejemplo, no basta con promover el acceso a servicios de salud sino dar paralelamente educación ya que, de lo contrario, no utilizarán 
los servicios de salud debido a factores culturales".

Destacamos también el trabajo Perú: inclusión $y$ exclusión social en la juventud, 2011, elaborado por Wilma Sandoval (2012), y publicado con los auspicios del INEI. La investigadora parte de la siguiente interrogante: ¿Cuáles son los factores que influyen significativamente en la exclusión social de los jóvenes?

En los resultados, la investigadora establece que, de un total de 8 millones, 717 mil jóvenes peruanos que tienen entre 15 y 29 años, la tercera parte se encuentran en situación de pobreza $(30.1 \%)$, siendo esta situación mayor en el área rural (54\%) que en el área urbana (19.2\%). Cabe destacar que la pobreza es mayor al interior del país.

$\mathrm{La}$ investigadora refiere que, en algunos departamentos, más de la mitad de los jóvenes se encuentran en situación de pobreza, siendo los casos de: Loreto (50 \%), Amazonas (52.6 $\%)$, Cajamarca $(50.7 \%)$, Huánuco (60. $7 \%$ ), Pasco (51.9 \%), Huancavelica (72.5 \%), Apurímac (64.4\%), Puno (54.2\%) y Ayacucho (55\%), departamentos que en su mayoría pertenecen a la región andina.

En otra parte de su trabajo, sostiene: "En el Perú, donde la desigualdad socioeconómica es la más significativa, y el contexto socio espacial es heterogéneo, $52,1 \%$ de jóvenes se encuentra en situación de exclusión social, lo que estaría condicionado por múltiples factores como pobreza, etnia, educación, mercado laboral, así como área de residencia." (p. 39).

Wilma Sandoval arriba a la siguiente conclusión: "De los resultados se desprende que los factores que están más consistentemente asociados a la exclusión social en la juventud peruana son el nivel educativo del joven y del jefe de hogar y, la situación de pobreza del hogar, situaciones que están estrechamente correlacionadas" (p. 51).

\section{DELIMITACIÓN CONCEPTUAL}

a. Ciudadano: Es el miembro de la sociedad civil que:

- Está incluido en el sistema político y ejerce el derecho a participar en la definición del sistema. - Participa en la construcción colectiva de la ciudadanía y la democracia en la sociedad civil y el Estado.

- Se beneficia de los derechos reconocidos legalmente y aspira al reconocimiento de otros.

b. Clase social: Grupo humano numeroso conformante de una sociedad heterogénea y que se diferencia de otros grupos por el lugar que ocupa en un sistema de economía social históricamente determinado por las relaciones respecto a la propiedad de los medios de producción, por su rol en la organización social del trabajo y por el modo y proporción en que participa de los bienes y servicios socialmente generados.

c. Conciencia social: Nivel de comprensión de la situación social que se vive y actitud de mejora continua de los miembros de un grupo, como resultado de una praxis social.

d. Democracia: En sentido estricto, democracia es la forma de gobierno del Estado, mediante la cual los ciudadanos eligen periódicamente a sus gobernantes para que los representen en la toma de decisiones relativas a la administración y conducción de país. Aquí se distingue una democracia directa de otra indirecta. Democracia directa, cuando la ciudadanía toma decisiones sobre asuntos de interés nacional mediante plebiscitos vinculantes, referéndums, iniciativas legislativas y votación de leyes. Democracia indirecta o representativa, cuando la ciudadanía delega en sus representantes la toma de decisiones. En ambos casos se trata de una democracia en lo político. En sentido amplio, democracia es un sistema de convivencia social donde los miembros de la sociedad civil son libres e iguales en derechos, $\mathrm{y}$ sus relaciones se rigen por mecanismos contractuales debidamente establecidos. Aquí se diferencia una democracia progresiva de otra integral. Con la democracia progresiva se aspira al reconocimiento global de los derechos, por lo que se tiende a la práctica de políticas de armonización de intereses de modo gradual. Con la democracia integral, se busca la participación plena de los miembros de la sociedad civil en igualdad de condiciones, en todas las áreas de la actividad 
nacional, ya sea en lo económico, político, social y cultural.

e. Desigualdad social. Concepto referido a las ventajas y desventajas que un individuo o grupo de individuos, por diversas causas (económicas, sociales, etc.), posee respecto a otros. Estas ventajas y desventajas abarcan desde la calidad de la alimentación, tipos de vivienda, acceso a los beneficios de la ciencia y la tecnología, hasta los niveles de la educación y grados del conocimiento, entre otros aspectos. En las sociedades de clases, las desigualdades sociales llevan a diferenciar a los grupos de individuos ricos de los grupos de individuos pobres. El concepto ubica a los grupos sociales en un esquema jerárquico de participación de la riqueza social.

f. Exclusión social. Acción y efecto de impedir la participación de ciertos grupos sociales en aspectos considerados como valiosos en o para la vida colectiva. Se diferencia exclusión económica de exclusión política o ciudadana y de exclusión cultural. La exclusión económica es la situación marginal de individuos y grupos sociales limitados o impedidos de participar activamente en los procesos productivos de las organizaciones económicas, por la naturaleza privatista de las políticas que las sustentan y, fundamentalmente, por el carácter del modo de producción del gran capital predominante. La exclusión política o ciudadana es la situación de los sujetos sociales que carecen de los derechos garantizados por una autoridad legítima, lo que les impide ejercer su libertad, participar en decisiones con autonomía y desenvolverse en la vida social (con la práctica de los derechos civiles, políticos, sociales, económicos y culturales). La exclusión cultural se expresa en dos formas: primero, como la marginación de ciertos sectores que no comparten los códigos básicos necesarios para interactuar en la colectividad (niveles de educación, idioma) y en la adhesión a valores; segundo, como la discriminación que diferencia categorías de personas que son percibidas como inferiores respecto a otras, y que reciben un trato diferenciado y humillante en sus relaciones sociales.

g. Identidad. Es el conjunto de rasgos que diferencian al sujeto o a un colectivo respecto de los demás. La identidad es ese algo que somos y que vamos siendo a partir de la interacción con otros entes significativos y con el contexto, lo que implica el conocimiento de nuestro origen y pertenencia; asimismo, el compartir nuestra historia, tradiciones, creencias, símbolos, valores, y modos de comportamiento. Como fenómeno individual, la identidad es la subjetividad que nos hace diferentes de los otros, aun sabiendo que nos parecemos a esos otros que nos rodean. Como fenómeno social, la identidad posibilita la integración de sujetos y colectivos de sujetos afines sobre la base de intereses culturales comunes, lo que deviene en la formación de identidades grupales, nacionales y supranacionales.

h. Modo de Producción. Condición en que se producen los diversos bienes y servicios necesarios para la satisfacción de las necesidades humanas. El modo de producción se constituye con la articulación de las fuerzas productivas y las relaciones de producción. Las fuerzas productivas son elementos necesarios para que se realice la producción; tales elementos son la fuerza de trabajo (hombres) y los medios de producción (materia prima, herramientas, equipos, infraestructura y tecnologías). Las relaciones de producción son vínculos que se establecen entre los individuos que intervienen en la producción de bienes y servicios; dichas relaciones equivalen a relaciones de propiedad y de trabajo, además implican relaciones de distribución, circulación y consumo, lo que en conjunto constituye la esfera económica. Para entender la manera cómo es que la riqueza se distribuye y se consume, es fundamental comprender las condiciones en las que se produce. El modo de producción no solo se refiere a la producción material, comprende 
los otros niveles de la estructura global de la sociedad: jurídico, político e ideológico. El modo de producción organiza la sociedad en una estructura determinante, en el largo plazo, y en una superestructura determinada por la anterior. En síntesis: el modo de producción de la vida material condiciona todo el proceso de la vida social. Históricamente, desde los orígenes de la humanidad, cuatro han sido los modos de producción predominantes: modo de producción de la comunidad primitiva, modo de producción esclavista, modo de producción feudal y modo de producción capitalista. Con la experiencia soviética se proyectó el modo de producción socialista.

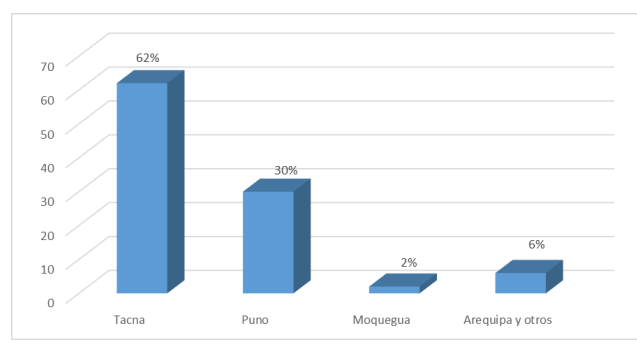

Figura 1. Porcentaje de respuestas a la pregunta: ¿En qué lugar del Perú nació Usted?

Una apreciación global de la Figura 1 nos lleva a distinguir que el $62 \%$ de los encuestados nacieron en Tacna, mientras que el $38 \%$ es inmigrante, siendo en mayor parte procedente de la región altiplánica, específicamente Puno. El registro censal de los últimos 55 años corrobora esta información.

De acuerdo a la información del INEI (Instituto Nacional de Estadística e Informática), el Censo Nacional de Población y Vivienda del año 2007 registró un total de 294965 habitantes en el departamento de Tacna, siendo 242670 residentes en la ciudad capital. El censo nacional del año 2017 registró 329332 habitantes en el departamento, ascendiendo a 286240 los residentes en la ciudad capital.

Se entiende que a Tacna ciudad-capital convergen los flujos migratorios de la región altiplánica y de otros lugares a partir de la existencia de causas impulsoras y causas atractivas. Entre las causas impulsoras priman las limitadas posibilidades de desarrollo interno y la carencia de fuentes de trabajo en los lugares de origen de los migrantes, particularmente las áreas rurales del extremo sur peruano afectadas por una prolongada sequía, lo que los induce a buscar otros horizontes. Entre las causas atractivas se encuentra un intenso comercio fronterizo y sus servicios colaterales que la ciudad de Tacna sostiene con la ciudad de Arica, en las particulares condiciones de zonas francas; además la creciente modernización de ambas ciudades ubicadas en la gran cuenca del Pacífico.

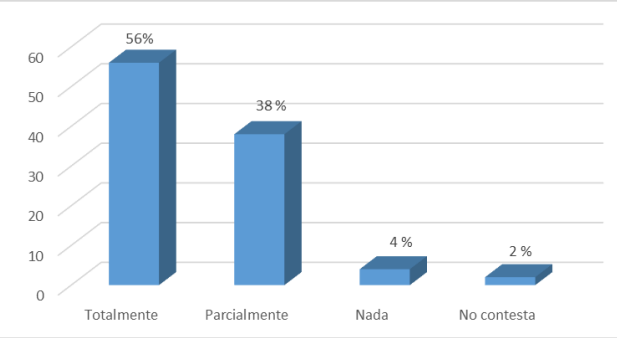

Figura 2. Porcentaje de respuestas a la pregunta: ¿Está usted orgulloso (a) de ser peruano (a)?

Teóricamente se entiende que el "orgullo de ser peruano" es una forma de expresión de la identidad nacional; sentirse satisfecho, bien, feliz por las riquezas y potencialidades del país; una forma de reconocerse como parte y partícipe de lo nacional relativo a su comunidad de gentes y sus virtudes, al territorio y sus recursos, a su patrimonio cultural, al interés social y a sus aspiraciones comunes.

Ahora, la información presentada en la Figura 2 pone al descubierto el debilitamiento de la identidad nacional en un porcentaje considerable de personas residentes en Tacna, ciudad fronteriza con el Estado chileno. Este debilitamiento de la identidad o la mengua del "orgullo de ser peruano" en Tacna guarda relación directa con los resultados de las figuras 4 y 5 (injusta distribución de la riqueza), y figura 6 (bajo ingreso familiar); condiciones materiales que afectan a quienes se encuentran en la base de la pirámide económica y social, vivenciando el drama de la situación-límite de la exclusión. En estas condiciones la vivencia del "orgullo de ser peruano" se debilita y deviene en un menoscabo identitario.

Este menoscabo identitario -ya vislumbrado en el comportamiento de ciertos individuos que, en las últimas décadas, optaron por la doble nacionalidad asumiendo la del Estado del sur para ser partícipes de ciertos beneficios 
económicos- debería concitar especial atención y tratamiento por parte de los gobernantes y conductores sociales, lo que implica prioridad en la aplicación de un política integral de fronteras vivas, por cuanto el menoscabo identitario en referencia afecta al desarrollo interno y al ejercicio de la soberanía nacional en toda su extensión.

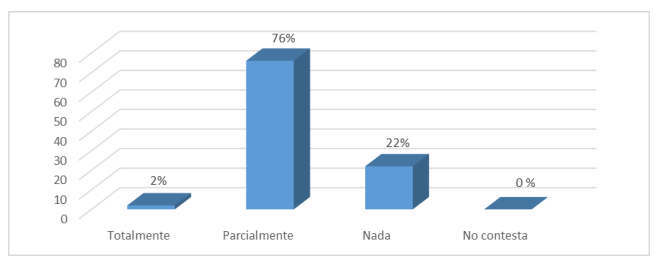

Figura 3. ¿Considera usted que actualmente la sociedad peruana es democrática?

Una primera lectura de la Figura 3 nos permite percibir que en el Perú se va generalizando el cuestionamiento a la práctica de la democracia liberal. En este sentido, el $76 \%$ de la población encuestada considera que la sociedad peruana es parcialmente democrática; el $22 \%$ la califica de nada democrática mientras que un reducido grupo de encuestados, que representa el $2 \%$, se inclina por afirmar que la sociedad peruana es totalmente democrática.

Para comprender la percepción y concepción de democracia en la respuesta de los encuestados que minimiza la vivencia de la democracia en la sociedad peruana, o simplemente la reduce en su práctica, es menester esclarecer qué es lo que se entiende por democracia, cómo se la practica en el Perú y cuáles son sus alcances; vale decir contrastar la teoría con la práctica. Y para esto, nos remitimos a nuestra delimitación conceptual donde se distingue: el sentido restringido de democracia como forma de gobierno y el sentido amplio de democracia como sistema de convivencia social.

Bien sabemos que en el país se ha impuesto la praxis de una democracia formal restringida a la renovación periódica de autoridades mediante el sufragio de los ciudadanos. Esta es la denominada democracia liberal aceptada, reclamada y promocionada por los grupos de poder que se ubican en la cúspide de la pirámide social y en la conducción del Estado. Todos ellos son co-partícipes de la implementación del modelo de economía liberal capitalista, cuya continuidad se asegura con el marco jurídico que sostiene el régimen de la democracia liberal.

Que una gran mayoría de encuestados (76\%) sostenga que la sociedad peruana es parcialmente democrática, muestra, por una parte, su desazón con el régimen de democracia liberal imperante, en tanto no soluciona los problemas fundamentales de sociedad nacional, menos los de Tacna largamente postergada; y, por otra parte, deja traslucir su inclinación por una democracia social de más amplia participación.

Aquí se debe destacar que durante el curso del siglo XX y en lo que va del presente, sectores del pueblo tacneño, evidenciando su condición de ciudadanía excluida, fueron partícipes de múltiples jornadas por sus reivindicaciones más sentidas, llegando a inclinar sus preferencias electorales por las agrupaciones políticas de orientación socialdemócrata, al calor de la prédica de reformas económicas y el Estado de bienestar. Las elecciones de 1931, $1945,1963,1985$ y 2011 fueron los momentos culminantes de esa orientación, aunque, después, sobrevino la frustración del ejercicio gubernamental. No obstante, cabe también incluir la experiencia de las elecciones para la Asamblea Constituyente que elaboró la Constitución socialdemócrata de 1979, con la variante que en Tacna la orientación fue socialista bajo el liderazgo del FOCEP (Frente Obrero Campesino Estudiantil y Popular).

Ahora, el resultado de la encuesta nos permite poner de relieve la tendencia histórica de la ciudadanía tacneña que se ubica en la base de la pirámide social: la tendencia por la construcción de una democracia como sistema de auténtica convivencia social. 


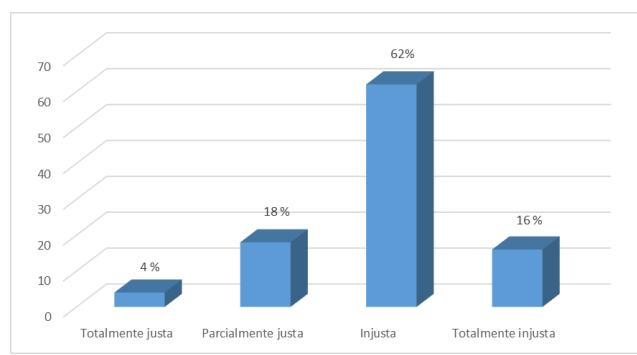

Figura 4. Porcentaje de respuestas a la pregunta: ¿Considera usted que la distribución de la riqueza en el Perú es...?

Una observación global a los resultados que registra la Figura 4, nos lleva a distinguir una reducida minoría de $4 \%$ de encuestados que considera totalmente justa la distribución de la riqueza en el Perú; contrariamente, la gran mayoría advierte el estado de una injusta distribución de la riqueza; claro está, con las especificaciones de injusta (62\%) y totalmente injusta (16\%), cuya sumatoria asciende al $78 \%$. Un grupo que asciende al $18 \%$ muestra cierta desazón con la distribución de la riqueza en el Perú, por lo que la califica de parcialmente justa.

Por los resultados que se registran se entiende que la mayoría de los encuestados vive y percibe, en lo cotidiano de su particular existencia y de la otredad, la injusta distribución de la riqueza, lo que en el ámbito nacional se constata con el acceso diferenciado a la propiedad, al extremo que unos pocos son grandes propietarios y satisfacen sus necesidades a plenitud, mientras que la mayoría se ve privada de la propiedad experimentando las consecuencias de la pobreza. Asimismo, una escala remunerativa que en el año 2017 fue desde un salario mínimo mensual de 850 soles (estando los pensionistas degradados por debajo de este salario mínimo) hasta arriba de los 30 mil y 50 mil soles a los que se hacen acreedores los altos funcionarios y magistrados que constituyen otra minoría de privilegiados. A esta situación de exclusión se agregan las personas subocupadas y desocupadas, minimizadas en su acceso a los beneficios del desarrollo nacional, con trabajos eventuales, bajo la permanente amenaza de los cortes laborales y los despidos intempestivos, llegando al extremo de su exclusión total.
Lo arriba expresado pone al descubierto la dramática realidad del fenómeno de exclusión económica que afecta a la población nacional y por extensión a la ciudad capital Tacna, con un nivel de alta concentración de activos económicos en manos de una minoría.

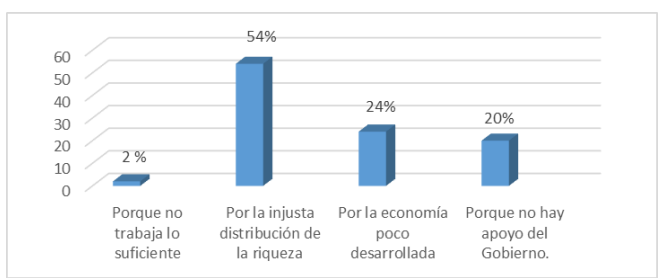

Figura 5. ¿Por qué considera usted que en el Perú la gente es pobre?

En la figura correspondiente, se presenta una variada información respecto al por qué de la pobreza en el Perú. Así, en primer lugar, se destaca que el $54 \%$ de los encuestados percibe que la gente es pobre por la injusta distribución de la riqueza, la misma que se vive y se constata en la cotidianeidad de la existencia humana.

En segundo lugar, se ubica el grupo que representa el $24 \%$ de los encuestados, el mismo que afirma que la gente es pobre por la existencia de una economía poco desarrollada, de lo que se infiere una economía poco diversificada, con oferta laboral reducida y con bajas remuneraciones, la misma que prolonga su carácter primario exportador.

El tercer grupo, que representa el $20 \%$, sostiene que la gente es pobre porque no hay apoyo del gobierno, lo que equivale a radicalizar el cuestionamiento del grupo anterior, pero demandando del gobierno, y más propiamente del Estado, el cumplimiento de su rol promotor del desarrollo nacional, vale decir que, por mandato constitucional, el Estado debe cumplir la función de "promover el bienestar general que se fundamenta en la justicia y en el desarrollo integral y equilibrado de la Nación" (Art. 44. de la Constitución Política del Perú).

Por último, se encuentra el $2 \%$ de los encuestados que considera que la gente es pobre "porque no trabaja lo suficiente", expresión lapidaria que ignora totalmente las posiciones de los grupos anteriores y, más aun, la dramática 
realidad contemporánea en la que campea la explotación del hombre por el hombre.

Por lo arriba expuesto se concluye que la gente es pobre por la injusta distribución de la riqueza, basada en relaciones producción igualmente injustas, lo que se agrava con la existencia de gobiernos que no asumen políticas de cambio estructural de nuestra economía.

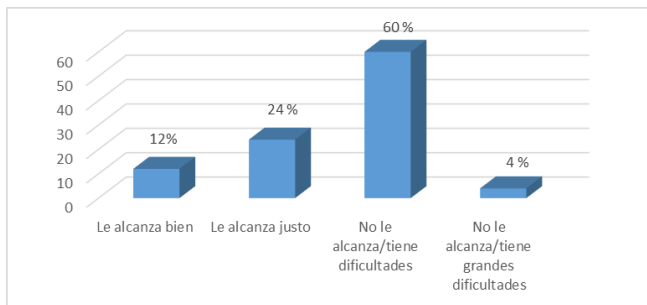

Figura 6. Porcentaje de respuestas a la pregunta: ¿En qué situación se encuentra su familia respecto al total del ingreso familiar?

La información presentada en la Figura 6, nos indica que la mayoría de la población se desenvuelve en los parámetros de una economía de subsistencia, caracterizada por los ingresos familiares que cubren las necesidades básicas de alimentación, vestimenta y vivienda con serias limitaciones.

Aquí, se debe puntualizar que la condición humana en el mundo no es subsistir, sino existir ganando en calidad de vida; pasar de una situación de permanencia de vida con limitación en la satisfacción de las necesidades hacia otra situación de mayor satisfacción conducente al bienestar: La sociedad de bienestar tantas veces prometida por políticos y conductores sociales.

Con ingresos familiares deprimentes no es posible avanzar en la mejora de la condición humana. Más aun esta situación tenderá a agravarse en tanto no se resuelva la injusta distribución de la riqueza.

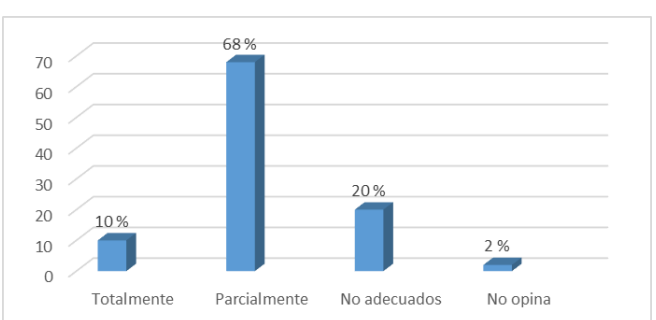

Figura 7. Porcentaje de respuestas a la pregunta: ¿Los programas sociales pensión 65, Beca 18 y Qali Warma son adecuados para combatir la pobreza?

La Figura 7 revela que la mayoría de los encuestados, $68 \%$, responde que los programas sociales (pensión 65, Beca 18, y Qali Warma) son parcialmente adecuados para combatir la pobreza. Solo el $10 \%$ manifiesta que son totalmente adecuados.

Los programas sociales, en referencia, fueron creados por el gobierno del Presidente Ollanta Humala Tasso, siguiendo la experiencia de las políticas asistencialistas desarrolladas en Brasil y Argentina. Tal es el caso de Pensión 65 para aquellas personas calificadas en condición de extrema pobreza, a partir de los 65 años de edad. Consistente en la entrega de 250 soles bimensuales, vale decir cuatro soles diarios, se pretendió la atención de sus necesidades básicas de alimentación, vivienda y vestido. Se conviene en aceptar que una persona vive en pobreza extrema cuando no tiene vivienda con servicios mínimos (agua potable, desagüe, energía eléctrica), se desplaza entre la subocupación y la desocupación captando eventualmente pequeños ingresos económicos $\mathrm{y}$, en consecuencia, se encuentra reducido a la condición de subalimentado.

El programa Pensión 65 fue magnificado por el Comandante Presidente. Sus allegados difundieron una encuesta con la cual se aseguró que el $93.8 \%$ de los usuarios del programa estrella había mejorado su vida con la subvención económica bimestral que le entregaba el Estado. 
La política de otros gobiernos de Latinoamérica, en sus esfuerzos por erradicar la pobreza, no ha presentado mayores logros con los programas de inclusión asistencialista. De aquí que se sostenga que, para abordar la erradicación de la pobreza, y con ella la desigualdad, se debe empezar con el cambio de las injustas relaciones de producción.

Respecto al programa nacional Beca 18, bajo administración del Ministerio de Educación, se debe precisar que este está dirigido a estudiantes talentosos provenientes de zonas de pobreza y "extrema pobreza", a quienes se beneficia con el acceso a carreras técnicas y profesionales en convenios con institutos y universidades. Expertos como Teresa Tovar y Hamer Villena (2013), al referirse a Beca 18 y otras modalidades (como Beca Presidente de la República), han coincidido en señalar que, si bien ambos programas de becas no solucionarían la real situación de la educación, sí sobresalen por sí solos como una medida del Estado que entregaría ayuda vital a los jóvenes de menores recursos.

El programa nacional de alimentación escolar Qali Warma surgió en remplazo del cuestionado PRONAA. Su objetivo es garantizar el servicio alimentario de los niños de instituciones educativas públicas de los niveles de inicial (a partir de los 3 años de edad) y primaria. Para lo cual, busca la participación de los padres de familia. La Confederación de Asociaciones de Padres de Familia ha denunciado múltiples casos en que los menores reciben alimentos sin las condiciones mínimas de seguridad para ser entregados y consumidos, y que algunos de esos alimentos son parte de una "alimentación chatarra". Asimismo, se ha cuestionado la falta de seguimiento continuo a este servicio.

Con la información presentada en las figuras anteriores y la que se aprecia en este comentario, se ratifica la tendencia a considerar que no son suficientes los programas de inclusión que se vienen implementando; menos aun cuando se reitera el combate por la reducción de la pobreza sin tomar en cuenta la reestructuración de la base económica, empezando por las injustas relaciones de producción.

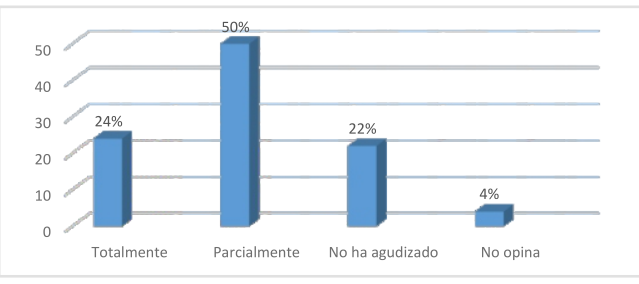

Figura 8. Porcentaje de respuestas a la pregunta: ¿El actual modelo económico ha agudizado las diferencias entre las clases sociales?

De acuerdo a la información de la Figura 8, se puede deducir que hay una tendencia a la aceptación que el actual modelo económico, si bien responde a los intereses de una minoría social encumbrada con la concentración de la riqueza, en general empeora las diferencias entre las clases sociales. Lo que se manifiesta con la persistencia del régimen por mantener la política de las diferencias salariales, la inestabilidad laboral, los programas sociales asistencialistas, las leyes, convenios y tratados que favorecen la acumulación del gran capital, particularmente en lo que beneficia a los grupos de poder interno y las grandes corporaciones trasnacionales.

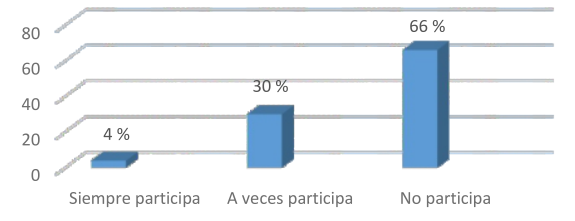

Figura 9. Porcentaje de respuestas a la pregunta: ¿Participa usted en alguna organización política?

En la Figura 9 se ratifica, una vez más, la información sobre la escasa o casi nula participación ciudadana en organización política alguna, llámense partidos o frentes, lo que es, a todas luces, sumamente negativo para la construcción de la democracia en el país, pero positivo para la dictadura del gran capital, y, en particular, favorable para la burocratización partidaria y/o la apropiación familiar de la organización política.

Así, en nuestra encuesta se puede observar que la gran mayoría de los entrevistados, que asciende al $66 \%$, no participa en organización política alguna, reflejando un alarmante 
desinterés por la actividad política y consecuentemente indiferencia por los asuntos del Estado, sus problemas y su gobernabilidad. Le sigue el $30 \%$ que a veces participa, vale decir eventualmente, sin ser parte de la membresía partidaria, más bien simpatizante, sin condiciones y sin compromisos. Por último, el $4 \%$ que siempre participa, que constituye la membresía, la militancia que asume compromisos y responsabilidades, que tiene derechos y deberes partidarios y que guarda la disciplina correspondiente.

Se entiende que los partidos políticos que aspiran a democratizar el Estado y la sociedad, estableciendo el bienestar común, tienen la alta misión de organizar, educar y conducir a los ciudadanos para el cumplimiento de tales propósitos.

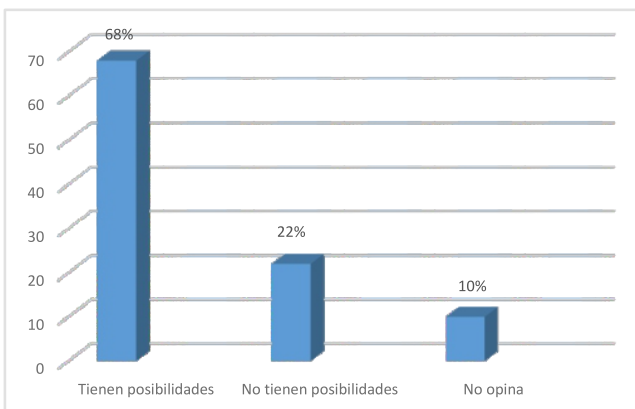

Figura 10. Porcentaje de respuestas a la pregunta: ¿Considera usted que la mayoría de los pobres en el Perú tienen o no tienen posibilidades de salir de la pobreza?

En la Figura 10, el $68 \%$ de los encuestados responde que sí hay posibilidades para salir de la pobreza. Contrariamente, para el $22 \%$ no hay posibilidades.

Si la mayoría de los encuestados comparten la situación de pobreza - o si se quiere niveles de pobreza- y abrigan la posibilidad de superar tal condición, entonces cuestión fundamental es saber cómo.

En las figuras 4 y 5 se pone de relieve la injusta distribución de la riqueza en el país y la pobreza como su consecuencia social, lo que además es una expresión deprimente de la desigualdad que afecta a la sociedad nacional. De la lectura de la Figura 8, que pone en cuestión el modelo económico vigente en tanto agudiza las diferencias sociales, se deriva la necesidad de un cambio de modelo económico. Asimismo, de la lectura de la Figura 3, donde se destaca la disconformidad con la democracia que se practica en el país, la democracia formal limitada a la renovación periódica de las autoridades, se deja abierta la posibilidad de una democracia integral de participación plena en todos los ámbitos de la actividad nacional, la democracia de convivencia social.

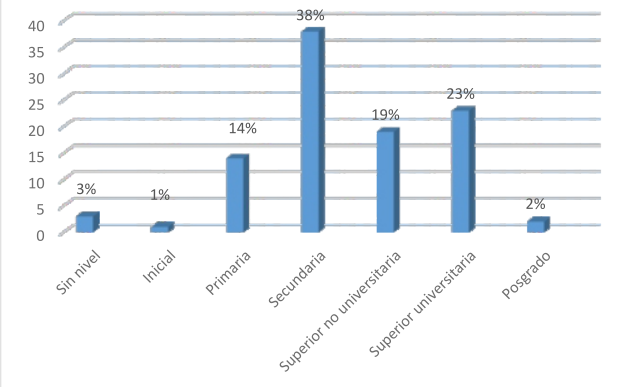

Figura 11. Porcentaje de respuestas a la pregunta: ¿Cuál es el nivel de educación alcanzado por Ud.?

Los resultados de la Figura 11 nos permiten afirmar que las tres cuartas partes de la población no accede al nivel de educación superior universitaria, que es (o debe ser) el nivel profesional por excelencia, lo que significa que el sistema excluye de las carreras profesionales a un amplio sector poblacional en la región. De cada 100 personas en la ciudad capital Tacna, solo 23 alcanzan a ser beneficiarias de las con rango universitario. Las razones que explican esta exclusión podemos advertirlas en:

a. Una limitada cobertura educacional: Situación condicionada por la disponibilidad de infraestructura, equipamiento y financiamiento. Funciona solo una universidad estatal con 30 carreras profesionales, cuya enseñanza es gratuita. Ocho universidades bajo regímenes privado y particular con pensiones de enseñanza diferenciadas, de las cuales, tres universidades con asistencia presencial (la más implementada con 21 carreras, las otras con menos de 15 carreras); por último, se agregan cinco universidades en las modalidades semipresencial y a distancia, con programas de irregular funcionamiento, situaciones que ponen en cuestión la calidad de sus servicios. 
b. Una oferta educacional en relativa relación con el mercado ocupacional. Se programan carreras sin el debido diagnóstico. No se precisa: ¿Cuántos profesionales se desempeñan en el área de su formación y cuántos están desocupados; además, cuántos están subocupados en el sentido de permanencia parcial y eventual, y cuántos se desempeñan en el área que no les corresponde? ¿Cuántos profesionales y de qué especialidad se habrá de necesitar en los próximos 5 y 10 años en cada una de las diversas áreas de la actividad regional y nacional?

Se afirma que una sociedad que moderniza su sistema educativo, diversifica sus servicios y los universaliza, garantiza la formación de sus profesionales con los que puede encontrar soluciones oportunas y adecuadas a los problemas que se presenten en el proceso de su evolución, lo que no pueden hacerlo sociedades sin esta perspectiva.

\section{DISCUSIÓN}

En primer lugar, valga precisar que por exclusión social entendemos a la acción y efecto de impedir la participación de ciertos grupos sociales, quienes disponen del poder, en aspectos considerados valiosos en y para la vida colectiva. Se diferencia exclusión económica de las exclusiones política y cultural.

Importa destacar que el factor económico es determinante en el desarrollo de los procesos sociales. En tal sentido, también nos permitimos precisar que la exclusión económica es la situación marginal de individuos y grupos sociales limitados o impedidos de participar activamente en los procesos productivos de las organizaciones económicas, por la naturaleza privatista de las políticas que las sustentan y, fundamentalmente, por el carácter de las relaciones de explotación en el modo de producción del gran capital predominante.

En Tacna, así como en el ámbito nacional, la exclusión económica afecta a un amplio sector de la población, siendo sus indicadores los siguientes:

1. Un acceso diferenciado a la propiedad y procesos productivos diversos, al extremo que unos pocos son los grandes beneficiados y los otros, que son la mayoría, tienen acceso limitado o no lo tienen.

2. Una escala de remuneraciones también diferenciada, que va desde el salario mínimo mensual de 850 soles que reciben los trabajadores del país (año 2017), aun incluyendo a los pensionistas que están por debajo de tal salario, hasta los altos funcionarios y magistrados que ganan sueldos arriba de los 30 mil y 50 mil soles mensuales (En marzo de 2018 el Presidente Kuczynski aumentó el salario mínimo a 930 soles).

3. Grupos de personas subocupadas y desocupadas cuya participación en los beneficios del desarrollo nacional se minimiza llegando hasta la exclusión total.

Entonces, tomando en cuenta los antecedentes expuestos, podemos comprender la respuesta de los encuestados referida a que en el Perú existe una injusta distribución de la riqueza, lo que genera la exclusión social y conduce a la desigualdad social, la misma que implica la fragmentación de la sociedad en clases y demás grupos entre hegemónicos, subordinados y excluidos o marginados. Vale decir, en la cúspide de la pirámide social se ubican los dueños y privilegiados de la riqueza; luego, descendiendo hacia la base de esta pirámide se encuentran los grupos humanos en condiciones de pobreza alarmante y pobreza extrema, según la tipología de uso actual.

Aquí, valga mencionar los resultados de la encuesta "Perils of Perception 2015" (Peligros de la percepción 2015), elaborada por IPSOS MORI (Reino Unido). "Los peruanos perciben que $32 \%$ de la riqueza está concentrada en el 1 $\%$ de la población; pero en realidad el $47 \%$ de la riqueza se concentra en el $1 \%$ de la población.

A la categoría exclusión social se asocia la categoría pobreza. Pobreza es una situación de menoscabo que indica tanto una ausencia de elementos esenciales para la subsistencia y el desarrollo personal, como insuficiencia de los instrumentos necesarios para abandonar aquella situación.

La gente es pobre por la existencia de una injusta distribución de la riqueza, basada en 
relaciones producción igualmente injustas, lo que se agrava aún más con la existencia de gobiernos que no asumen políticas de cambio estructural de nuestra economía.

Como es de conocimiento general, al margen de la fallida experiencia del general Velazco con sus reformas estructurales, en el Perú se ha pretendido una reducción de la pobreza con políticas de empleo temporal, entrega de alimentos y subsidios diversos. En esta línea se ubican los programas sociales creados por el gobierno del comandante Ollanta Humala (2011-2016), aplicando modelos de política populista ensayados en Brasil, Argentina y otros países de Latinoamérica. Tal es el caso de Pensión 65 con entregas de 250 soles bimensuales para las personas calificadas en condición de extrema pobreza a partir de los 65 años de edad, con lo que se asegura, según se afirmó en su momento, la atención de sus necesidades básicas. El gobierno demagógico publicitó que el $93.8 \%$ de los usuarios de Pensión 65 aseguró que su vida había mejorado con la subvención económica bimestral que le entrega el Estado. ¿Cuánto habría de significar una mejora de vida con cuatro soles diarios? Se conviene en aceptar que una persona vive en pobreza extrema cuando no tiene vivienda con servicios mínimos, se desplaza entre la subocupación y la desocupación captando eventualmente pequeños ingresos económicos, consecuentemente su condición es la de subalimentado.

Consideramos que para la reducción de la Pobreza (y mejor hasta su eliminación) no son suficientes los programas de inclusión asistencialista. Hay que abordar la reestructuración de la base económica, empezando con el cambio de las injustas relaciones de producción.

Otras formas de exclusión social son la política y la cultural. Por nuestros encuestados, identificamos un alto porcentaje de no participación ciudadana en las organizaciones políticas, canales naturales orientados a facilitar el acceso a los asuntos de funcionamiento del estado, sus problemas y su gobernabilidad.

Alguna vez, el historiador Jorge Basadre calificó al Perú como una "república sin ciudadanos". Ahora se habla de ciudadanías excluidas, ausentes e inconclusas. $\mathrm{Si}$ nos remitimos a nuestra Delimitación Conceptual, encontramos que: "Ciudadano es el miembro de la sociedad civil, que está incluido en el sistema político y que ejerce sus derechos a participar plenamente en la definición del sistema. Participa en la construcción colectiva de la democracia en la sociedad civil y en el Estado. Se beneficia de los derechos reconocidos legalmente y aspira al reconocimiento de otros".

Por lo expuesto, surge la siguiente interrogante: ¿Qué es lo que está determinando la exclusión ciudadana de las organizaciones políticas, y en consecuencia de la construcción de una sociedad democrática? En realidad, la respuesta no es una sola. El dato empírico nos permite identificar varios factores causales. Precisemos las siguientes:

1. Crisis de organización y funcionamiento de las entidades políticas, lo que se manifiesta como burocratismo partidario, carencia de instrumentos normativos, estructura orgánica anquilosada, falta de democracia interna y falta de promoción de sus cuadros directivos, además de reducción de su funcionamiento institucional al tiempo inmediato de su participación en los procesos electorales.

2. Falta de formación ideológica y capacitación ciudadana al interior de las organizaciones políticas. La imposición del dogmatismo y el sectarismo elimina el análisis, reflexión, teorización, debate y toda forma de innovación a favor de la praxis política. Las organizaciones políticas deberían asumir la función de educación ciudadana de su membresía en toda su extensión, preparándola para un eventual desempeño en la conducción del Estado.

3. Percepción negativa de la política. Conceptuada como ciencia de la administración del Estado, la política en los últimos tiempos ha devenido en una práctica utilitaria, mercantilista, en ciertos casos improvisada, al servicio de intereses particulares y mezquinos, en 
abierta contradicción con el bien común.

4. Desvinculación de la praxis política con la realidad en todas las áreas de la actividad nacional y su relación con el exterior, pretextando actitudes imparciales, neutrales o independientes.

Urge la reconstrucción de las organizaciones políticas para que contribuyan a la más amplia educación de la ciudadanía, a fin de asegurar su participación en el establecimiento de la democracia integral como sistema de convivencia.

Respecto a la exclusión cultural, el trabajo de investigación nos permite visualizar que las tres cuartas partes de la población no accede al nivel de educación universitaria, que es el nivel profesional por excelencia. De cada 100 personas en la ciudad capital Tacna, solo 23 incursionan en las carreras profesionales con rango universitario. ¿Cuántos de los que egresan se titulan? ¿Cuántos obtienen posgrados y especialización?

El porqué del reducido grupo que accede al nivel profesional, habría que buscarlo en los siguientes condicionantes:

1. Limitada cobertura educacional: Con insuficiente infraestructura, equipo y financiamiento, en la ciudad de Tacna funcionan regularmente nueve universidades: una de ellas estatal con 30 carreras profesionales, cuya enseñanza es gratuita; las otras ocho universidades bajo regímenes privado y particular con pensiones de enseñanza diferenciadas, de las cuales tres con asistencia presencial (una más implementada con 21 carreras, las otras con menos de 15 carreras); por último, cinco universidades con modalidades semi presencial y a distancia lo que condiciona su calidad.

2. Oferta de carreras profesionales sin un diagnóstico del mercado ocupacional: ¿Cuántos profesionales están ocupados en el área de su formación? ¿Cuántos están subocupados temporal o eventualmente? ¿Cuántos están subocupados en otra área? ¿Cuántos profesionales se requerirán para los próximos 5 y 10 años en cada una de las áreas de la actividad regional y también nacional?

Si queremos pasar de una sociedad jerarquizada y excluyente a una sociedad democrática e inclusiva, se requiere de una población ciudadana ascendente al nivel de educación superior, con capacidad para cuestionar con fundamentos, exigir el cumplimiento de las reivindicaciones sociales postergadas y asumir el compromiso de su desempeño profesional en las funciones públicas que demanden de su competencia.

El estudio del fenómeno de la exclusión social en sus tres formas: económica, política y cultural, sobre la base de la información empírica de nuestros encuestados y el soporte teórico metodológico que guía nuestro trabajo de investigación, nos ha permitido comprobar la directa relación entre la exclusión social y la desigualdad social, fenómenos que se generan y acentúan en toda sociedad de clases.

Cabe precisar que, la desigualdad social es un concepto referido a las ventajas y desventajas que un individuo o grupo de individuos por diversas causas posee respecto a otros. Estas ventajas y desventajas abarcan desde la calidad de la alimentación, tipos de vivienda, acceso a los beneficios de la ciencia y la tecnología, hasta los niveles de la educación y grados del conocimiento, entre otros aspectos. En las sociedades de clases, las desigualdades llevan a diferenciar a grupos de individuos ricos a grupos de individuos pobres. En Tacna, ciudad que se moderniza con el comercio fronterizo en condiciones de zona franca, también se experimenta el fenómeno de la desigualdad social que fragmenta la sociedad.

Las desigualdades sociales generan intereses y aspiraciones entre los grupos que se contraponen, derivando en conflictos denominados luchas sociales. Las desigualdades fragmentan la sociedad y ponen en riesgo la permanencia de sus identidades, llevándola a su debilitamiento y hasta su extinción.

Este es el caso de Tacna, una ciudad fronteriza 
ubicada en el extremo sur peruano, colindante con el Estado de Chile. Convergen en esta ciudad los flujos migratorios de la región altiplánica y de otros lugares del país y del exterior. Un alto porcentaje de inmigrantes, que asciende al $38 \%$ (Figura 1), conforman su población que asciende a 270500 habitantes, siendo en su mayor parte procedente de la región altiplánica.

Históricamente, se ha reconocido al pueblo tacneño por su acendrado sentimiento patrio y espíritu nacionalista. En los inicios de la República, siendo Presidente el General José de La Mar, se declaró a Tacna "Heroica Ciudad" por Ley del 26 de mayo de 1828, luego de considerar que la Villa de Tacna había prestado servicios distinguidos a la causa de la independencia. Posteriormente, ya en situaciones límite como la guerra con Chile y la subsiguiente ocupación militar de una parte del territorio de Tacna por 49 años, tres meses y un día, el pueblo tacneño dio una sublime muestra de lucha y resistencia por el mantenimiento de su identidad con lo nacional.

Ahora, con la información presentada en la Figura 2, se pone al descubierto el debilitamiento de la identidad nacional en un porcentaje considerable de personas residentes en Tacna. Este debilitamiento de la identidad o la mengua del "orgullo de ser peruano" guarda relación directa con los resultados de las figuras 4 y 5 (injusta distribución de la riqueza), y Figura 6 (bajo ingreso familiar); condiciones materiales que afectan a quienes se encuentran en la base de la pirámide económica y social, vivenciando el drama de la situación-límite de la exclusión. En esta perspectiva, la vivencia del "orgullo de ser peruano" se debilita y deviene en un menoscabo identitario.

La opción de algunos tacneños por la doble nacionalidad, asumiendo la del Estado del sur para ser partícipes de ciertos beneficios económicos, debería concitar especial atención por parte de los gobernantes y conductores sociales, por cuanto el menoscabo identitario afecta al desarrollo interno y al ejercicio de la soberanía nacional en toda su extensión.

En Tacna ciudad fronteriza, en la que convergen fuertes flujos migratorios, la exclusión social acentúa la desigualdad social, y esta, a su vez, pone en riesgo la identidad empezando por su dimensión individual.

Finalmente, no obstante el alto porcentaje de no participación ciudadana en las organizaciones políticas, canales naturales y más convenientes para acceder a los asuntos de funcionamiento del Estado, sus problemas y su gobernabilidad (Figura 9), se abriga la esperanza que los pobres puedan superar su condición (Figura 10), en suma, la crítica situación de desigualdad que afecta a la sociedad tacneña y peruana. ¿Cómo? En la figura 8 se advierte cierto nivel de disconformidad que resta crédito al modelo económico de orientación liberal, lo que compromete la percepción del $74 \%$ de los encuestados. Asimismo, en las figuras 4 y 5 se advierte desazón y rechazo a la injusta distribución de la riqueza basada en relaciones producción igualmente injustas.

De lo anterior se infiere la necesidad de un cambio radical de la sociedad peruana, empezando por el cambio de las injustas relaciones sociales de producción. Tal cambio incidiría en la superación de la exclusión social y con ella la desigualdad social.

\section{CONCLUSIONES}

En toda sociedad concreta la exclusión social, generada a partir de la injusta distribución de la riqueza, conduce a la desigualdad social, la misma que implica la fragmentación de la sociedad en clases y demás grupos entre hegemónicos, subordinados y marginados.

Hay una tendencia de rechazo creciente al actual modelo económico liberal, bajo el cual se han conducido los sucesivos gobiernos en el país, debido a que mantiene las exclusiones y acentúa las desigualdades sociales.

En Tacna, ciudad fronteriza, la desigualdad social pone en serio riesgo a la identidad, empezando por su dimensión individual.

Se distingue en la ciudadanía tacneña, que se ubica en la base de la pirámide social, la tendencia histórica por la construcción de una democracia como sistema de convivencia que 
supere tanto la exclusión como la desigualdad social en todas sus formas.

\section{RECOMENDACIONES}

Cambiar el modelo económico: Estando próximos a los 200 años de vida republicana, es fundamental que las organizaciones políticas aspirantes a conducir el Estado con soberanía y democracia, asuman el compromiso de cambio del modelo económico liberal que hasta ahora mantiene las exclusiones y acentúa las desigualdades sociales.

Educar al ciudadano. Las organizaciones políticas deben desarrollar la educación ciudadana para que su membresía participe con responsabilidad y competencia en los asuntos que demande la sociedad civil y el Estado.

Implementar la investigación científica. Las escuelas de formación profesional deben implementar líneas de investigación científica que tengan por ejes temáticos: Ciudadanía y Democracia, Soberanía y Desarrollo, Identidad y Valores.

Complementar la formación profesional con la formación ciudadana. Superando la vieja concepción de las escuelas como instituciones neutrales que solo forman profesionales para su incorporación al mercado laboral, las diversas escuelas de la Universidad del siglo XXI deben innovar sus planes curriculares de tal manera que la formación profesional se complemente con la formación ciudadana o política. Los nuevos profesionales serán los nuevos ciudadanos que en algún momento asumirán responsabilidades sociales.

\section{REFERENCIAS}

De los Ríos, D. (1996). Exclusión social y políticas sociales: Una mirada analítica, en Lecturas sobre la exclusión social. Publicación de la Oficina Internacional del Trabajo, en Santiago de Chile.

IPSOS MORI (Reino Unido). Encuesta "Perils of Perception 2015" (Peligros de la percepción 2015). Disponible en: http://blogs.gestion.pe/sostenibilidada plicada/2016/03/

PERÚ Gobierno Central. (2015). Cuál es el impacto de los Programas Sociales. D i s p o n i b l e e n : elcomercio.pe/sociedad/Peru/cualimpacto

Roca Rey, I. y Rojas, B. (2002). Pobreza y exclusión social: una aproximación al caso peruano. Boletín del Instituto Francés de Estudios Andinos, 31(3).

Sandoval, W. (2011). Perú: inclusión y exclusión social en la juventud, 2011. Lima: INEI.

Sulmont, D. (1995). Exclusión social y empleo: notas para un debate. En Globalización y empleo. Editorial ADECATC. Dispoible en: www.academia.edu $>$ Exclusión_socia 1_y_empleo

Tovar, T. y Villena, H. (29 de julio de 2013). Más beneficiarios de Beca 18 en el 2016. Diario La Primera, p. 20. 